\title{
Formation mechanisms and atomic configurations of nitride phases at the interface of aluminum nitride and titanium
}

\author{
Chia-Hsiang Chiu and Chien-Cheng Lin $^{\text {a) }}$ \\ Department of Materials Science and Engineering, National Chiao Tung University, \\ Hsinchu 30050, Taiwan
}

(Received 6 March 2008; accepted 5 May 2008)

\begin{abstract}
Aluminum nitride was bonded with a titanium foil at $1400^{\circ} \mathrm{C}$ for up to $1 \mathrm{~h}$ in Ar. The AlN/Ti interfacial reactions were investigated using analytical electron microscopy. Reaction layers, consisting of $\delta-\mathrm{TiN}, \tau_{2}-\mathrm{Ti}_{2} \mathrm{AlN}, \gamma-\mathrm{TiAl}, \alpha_{2}-\mathrm{Ti}_{3} \mathrm{Al}$, a two-phase region $\left(\alpha_{2}-\mathrm{Ti}_{3} \mathrm{Al}+\alpha-\mathrm{Ti}\right)$, and $\alpha$-Ti $(\mathrm{Al}, \mathrm{N})$ solid solution, were observed after annealing at $1400{ }^{\circ} \mathrm{C}$ for $0.1 \mathrm{~h}$. Among these phases, the $\alpha_{2}-\mathrm{Ti}_{3} \mathrm{Al}$ and $\left(\alpha_{2}-\mathrm{Ti}_{3} \mathrm{Al}+\alpha-\mathrm{Ti}\right)$ were formed during cooling. Further diffusion of $\mathrm{N}$ atoms into the reaction zone precipitates a chopped fiber-like $\alpha_{2}-\mathrm{Ti}_{2} \mathrm{AlN}$ in the matrix of $\gamma$-TiAl, with $[110]_{\gamma-\mathrm{TiAl}} / /[11 \overline{2} 0]_{\tau_{2}-\mathrm{Ti}_{2} \mathrm{AlN}}$ and $(1 \overline{1} \overline{1})_{\gamma-\mathrm{TiAl}} / /(1 \overline{1} 0 \overline{3})_{\tau_{2}-\mathrm{Ti}_{2} \mathrm{AlN}}$, by substituting $\mathrm{N}$ atoms for one-half $\mathrm{Al}$ atoms after annealing at $1400{ }^{\circ} \mathrm{C}$ for $1 \mathrm{~h}$. The released $\mathrm{Al}$ atoms, due to the precipitation of $\tau_{2}-\mathrm{Ti}_{2} \mathrm{AlN}$, resulted in an ordered Al-rich $\gamma$-TiAl or $\mathrm{Ti}_{3} \mathrm{Al}_{5}$. Furthermore, the $\alpha$-Ti $(\mathrm{Al}, \mathrm{N})$ was nitridized into a lamellar layer $(\delta$-TiN $+\alpha-\mathrm{Ti})$ with $[110]_{\delta-\mathrm{TiN}} / /[11 \overline{2} 0]_{\alpha-\mathrm{Ti}}$ and $(111)_{\delta-\mathrm{TiN}} / /(0001)_{\alpha-\mathrm{Ti}}$.
\end{abstract}

\section{INTRODUCTION}

The interfacial reactions of the AlN/Ti system have attracted a substantial amount of attention in the last few years since the AlN/Ti joints are used for microelectronic packaging and some high-temperature applications. ${ }^{1-6}$ Interfacial reactions between $\mathrm{Ti}$ and $\mathrm{AlN}$ are of great interest due to the high affinity of $\mathrm{Ti}$ to $\mathrm{Al}$ and $\mathrm{N}$, leading to formation of various nitrides and titanium aluminides. To obtain reliable mechanical properties of AlN and Ti joints, understanding the interfacial reactions between AlN and Ti is highly desirable for the design and processing of AlN/Ti bonding or joints.

Previous studies on the AlN/Ti interface shed light on the microstructural development of the reaction zone for various forms of starting materials, such as powders, ${ }^{1,2,4}$ thin films, ${ }^{5,7-9}$ and bulk materials. ${ }^{10}$ Pinkas et al. ${ }^{5}$ investigated the early stages of interfacial reactions between AlN(film) and $\mathrm{Ti}$ (film) after annealing at $600{ }^{\circ} \mathrm{C}$ for 1-10 h, showing that the AlN film reacted with $\mathrm{Ti}$ to form a phase sequence of $\mathrm{AlN} / \mathrm{TiAl}_{3} / \mathrm{Ti}_{2} \mathrm{~N} / \alpha_{2}-\mathrm{Ti}_{3} \mathrm{Al} /$ $\alpha-\operatorname{Ti}(\mathrm{Al}, \mathrm{N})$ solid solution. El-Sayed et al. ${ }^{9}$ indicated that the diffusion path followed the route of $\delta$-TiN $/ \tau_{1^{-}}$ $\mathrm{Ti}_{3} \mathrm{AlN} / \alpha_{2}-\mathrm{Ti}_{3} \mathrm{Al}$ between 20 - and $50-\mu \mathrm{m}$-thick Ti foils and AlN plates after annealing at $1050-1200{ }^{\circ} \mathrm{C}$ for 1-20 h, while $\tau_{2}-\mathrm{Ti}_{2} \mathrm{AlN}$ was formed following the com-

\footnotetext{
a) Address all correspondence to this author.

e-mail: chienlin@faculty.nctu.edu.tw

DOI: $10.1557 / J M R .2008 .0268$
}

plete consumption of Ti. Paransky et al. ${ }^{1,2,4}$ found that $\delta$-TiN and $\tau_{1}-\mathrm{Ti}_{3} \mathrm{AlN}$ exhibited a complex interpenetrating morphology at the $\mathrm{AlN}$ (powder)/Ti(powder) interface, as well as in the AlN/Ti diffusion couple after annealing at $900-1100{ }^{\circ} \mathrm{C}$. In addition, a two-phase $\left(\tau_{1}\right.$ $\mathrm{Ti}_{3} \mathrm{AlN}+\alpha_{2}-\mathrm{Ti}_{3} \mathrm{Al}$ ) layer was observed between $\tau_{1^{-}}$ $\mathrm{Ti}_{3} \mathrm{AlN}$ and $\alpha_{2}-\mathrm{Ti}_{3} \mathrm{Al}$ layers after annealing at 1000 $1100^{\circ} \mathrm{C}$. Microstructural characterization of the AlN/Ti interfaces has often been conducted using scanning electron microscopy (SEM) and x-ray diffraction (XRD), in spite of the overwhelming advantages of analytical transmission electron microcopy (TEM) including simultaneous image observation, compositional, and crystal structural analyses.

Recently, based on TEM microanalyses, Chiu and $\operatorname{Lin}^{10}$ revealed that $\delta$-TiN, some ternary compounds (i.e., $\tau_{2}-\mathrm{Ti}_{2} \mathrm{AlN}$ and/or $\tau_{1}-\mathrm{Ti}_{3} \mathrm{AlN}$ ), and distinctive $\mathrm{Ti}-\mathrm{Al}$ layers (i.e., $\gamma$-TiAl and/or $\alpha_{2}-\mathrm{Ti}_{3} \mathrm{Al}$ ) were formed in the AlN/Ti diffusion couple after annealing at 1300$1500{ }^{\circ} \mathrm{C}$. It was reported that $\tau_{2}-\mathrm{Ti}_{2} \mathrm{AlN}$ was formed between AlN and Ti after annealing at temperatures above $1300{ }^{\circ} \mathrm{C}$. Imanaka and Notis ${ }^{7}$ found that the formation activation energy of $\tau_{2}-\mathrm{Ti}_{2} \mathrm{AlN}$ between $\mathrm{AlN}$ and $\mathrm{Ti}$ thin films was $224 \mathrm{~kJ} / \mathrm{mol}$ at temperatures ranging from 800 to $850{ }^{\circ} \mathrm{C}$, which approximated that of the diffusion of $\mathrm{N}$ atoms in $\alpha-\operatorname{Ti}(\mathrm{Al})$. This implied that the formation of $\tau_{2}-\mathrm{Ti}_{2} \mathrm{AlN}$ was controlled by the diffusion of $\mathrm{N}$ atoms in $\alpha-\mathrm{Ti}(\mathrm{Al})$. Even though the nitridization of various $\mathrm{Ti}-\mathrm{Al}$ layers is likely to play a critical role, its effect on the microstructural development at the AlN/Ti interface has not been investigated to date. 
In another respect, nitridization experiments have been conducted on some Ti-Al intermetallic compounds such as $\gamma$-TiAl and/or $\alpha_{2}-\mathrm{Ti}_{3} \mathrm{Al}$, leading to the formation of various nitrides on their surfaces with subsequent improvements of their mechanical properties. ${ }^{11-14}$ Saito and Matsushima ${ }^{15}$ showed that implanted nitrogen atoms could react with $\gamma$-TiAl, resulting in the formation of $\mathrm{Ti}_{2} \mathrm{~N}$ and AlN. Zhao et al. ${ }^{11}$ observed $\delta$-TiN, $\tau_{2}-\mathrm{Ti}_{2} \mathrm{AlN}$, some new nitrides (such as $\eta-\mathrm{Ti}_{3} \mathrm{~N}_{2-x}$ and $\mathrm{Ti}_{2} \mathrm{~N}$ ), and Al-rich intermetallic phases (such as $\mathrm{Ti}_{2} \mathrm{Al}_{5}, \mathrm{TiAl}_{3}$, and $\mathrm{TiAl}_{2}$ ) when $\gamma$-TiAl-based alloys were nitridized in ammonia atmosphere after annealing at temperatures ranging from 800 to $940{ }^{\circ} \mathrm{C}$. Tian and Nemoto ${ }^{12}$ observed that needlelike $\tau_{1}-\mathrm{Ti}_{3} \mathrm{AlN}$ precipitated after the $\mathrm{L} 1_{\mathrm{o}^{-}}$ ordered $\gamma$-TiAl was nitridized at $800{ }^{\circ} \mathrm{C}$. The needlelike $\tau_{1}-\mathrm{Ti}_{3} \mathrm{AlN}$ phase was further replaced by plate-like $\tau_{2^{-}}$ $\mathrm{Ti}_{2} \mathrm{AlN}$ after aging at higher temperatures or for longer periods.

The interfacial reaction layers are thoroughly investigated using analytical TEM as well as SEM in this study. Two AlN plates are bonded with a thin Ti foil, so that a relatively large amount of $\mathrm{N}$ atoms are able to diffuse into the thin metal foil, wherein various $\mathrm{Ti}-\mathrm{Al}$ reaction layers are formed at an early stage. The main purpose of this investigation is to shed light on the role of $\mathrm{N}$ atom inward diffusion into $\mathrm{Ti}-\mathrm{Al}$ reaction layers in the microstructural evolution at the AlN/Ti interface. The phasetransformation mechanisms at the AlN/Ti interface are explained in terms of atomic configurations from the viewpoint of the nitridization of $\mathrm{Ti}-\mathrm{Al}$ intermetallic compounds mentioned in previous studies.

\section{EXPERIMENTAL PROCEDURES}

The starting materials were AlN plates (nominal composition of $62.8 \mathrm{wt} \% \mathrm{Al}, 32.1 \mathrm{wt} \% \mathrm{~N}, 3.4 \mathrm{wt} \% \mathrm{Y}$, 1.7 wt\% O; SH-15, Tokuyama Soda Corp., Tokyo, Japan) and Ti foils (99.7 wt\% in purity, $200 \mu \mathrm{m}$ in thickness; Alfa Aesar, Ward Hill, MA). AlN plates and Ti foils were cut into pieces with dimensions of $15 \mathrm{~mm} \times$ $10 \mathrm{~mm} \times 4 \mathrm{~mm}$ and $15 \mathrm{~mm} \times 10 \mathrm{~mm} \times 200 \mu \mathrm{m}$, respectively. Specimen surfaces were ground with a diamondmatted disc and polished with diamond pastes of 6,3 , and $1 \mu \mathrm{m}$ in sequence using a precision polishing machine (Model Minimet 1000, Buehler Ltd., Lake Bluff, IL). The specimens were then rinsed ultrasonically, first in an acetone bath and then in distilled water, prior to diffusion bonding. One Ti foil was inserted in between two AIN plates. The sandwiched specimens were then diffusionbonded in a hot press furnace (Model HP50-MTG-7010, Thermal Techno. Inc., Santa Rosa, CA). The working chamber was pre-evacuated to $1 \times 10^{-4} \mathrm{~Pa}$ and purged with Ar to $1 \mathrm{~atm}$ three times. The bonding conditions were $1400{ }^{\circ} \mathrm{C}$ for up to $1 \mathrm{~h}$ using a 2-MPa bonding pres- sure in an Ar atmosphere. The specimens were cooled down to room temperature at a rate of $10 \% \mathrm{~min}$.

The cross-sectional SEM specimens were cut perpendicular to the AlN/Ti interface. They were ground with a diamond-matted disc and polished with diamond pastes using the aforementioned procedure for further microanalyses by standard metallographic procedures. The cross-sectional TEM specimens of the AlN/Ti interface were prepared by two methods. First, they were cut perpendicular to the interface and then polished, dimpled, and subsequently ion-beam-thinned using a precision ion-polishing system (PIPS, Model 691, Gatan, San Francisco, CA). The details of this traditional technique for preparing cross-sectional TEM specimens were described in a previous study. ${ }^{10}$ Second, the samples were acquired by an innovative technique, whereby a specific location on a metallographic sample was ion-bombarded using a focused ion beam (FIB, Model Nova 200, FEI Co., Hillsboro, OR). The FIB operating parameters were as follows: the electron beam was $5 \mathrm{keV}$ from 98 to $1.6 \mathrm{~Pa}$, and the ion beam was $30 \mathrm{keV}$ at $7-10 \mathrm{~Pa}$. A thin TEM specimen was acquired along the direction perpendicular to the surface of a cross-sectional SEM specimen. The TEM specimen must be thinner than $100 \mathrm{~nm}$ to be electron-transparent. The final TEM specimen was approximately $20 \mu \mathrm{m} \times 10 \mu \mathrm{m} \times 0.1 \mu \mathrm{m}$ in size.

Microstructural characterization was carried out using a scanning electron microscope (SEM, Model JSM-6500, JEOL, Tokyo, Japan) and a transmission electron microscope (TEM, Model 2000Fx, JEOL), both attached with a characteristic x-ray energy-dispersive spectrometer (EDS, Model 9900, EDAX International, Prairie View, IL). Quantitative analyses of the chemical compositions for various phases were conducted by the Cliff-Lorimer standardless technique. ${ }^{16}$ Relative errors were estimated at $1 \%$ for concentrated elements and at more than $10 \%$ for diluted elements. Analyses of atomic configurations for various phases were performed using computersimulation software for crystallography (CaRIne Crystallography 3.1, C. Boudias and D. Monceau, Senlis, France).

\section{RESULTS AND DISCUSSION}

Figure 1(a) displays an SEM micrograph of the cross section of the AlN/Ti/AlN specimen after annealing at $1400{ }^{\circ} \mathrm{C}$ for $0.1 \mathrm{~h}$, indicating that the interfacial reaction zone in the AlN/Ti/AlN specimen consists of $\delta$-TiN, $\tau_{2}-\mathrm{Ti}_{2} \mathrm{AlN}, \gamma-\mathrm{TiAl}, \alpha_{2}-\mathrm{Ti}_{3} \mathrm{Al}$, a two-phase region $\left(\alpha_{2^{-}}\right.$ $\left.\mathrm{Ti}_{3} \mathrm{Al}+\alpha-\mathrm{Ti}\right)$, and $\alpha-\mathrm{Ti}(\mathrm{Al}, \mathrm{N})$ in sequence after annealing at $1400{ }^{\circ} \mathrm{C}$ for $0.1 \mathrm{~h}$. The phase sequence in Fig. 1(a) was the same as that found in the AlN/Ti diffusion couple after annealing at $1400{ }^{\circ} \mathrm{C}$ for $3 \mathrm{~h}$ as mentioned previously, ${ }^{10}$ where the microstructures were characterized using analytical TEM and SEM. It was attributed to the fact that that the thickness of $\mathrm{Ti}$ in the AlN/Ti/AlN 


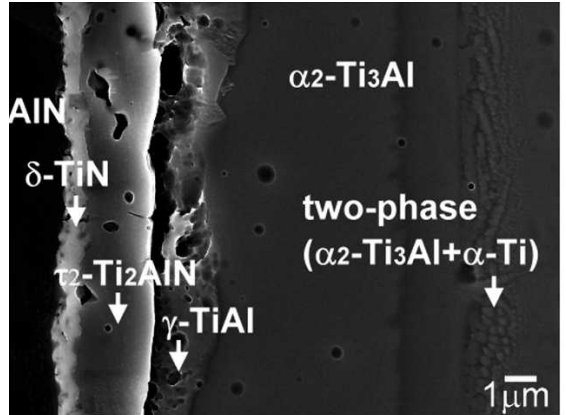

(a)

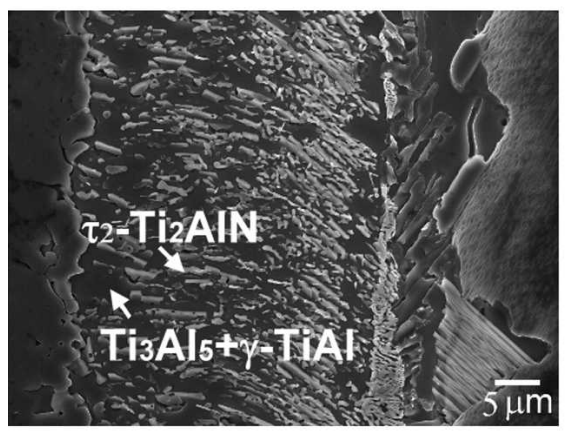

(c)

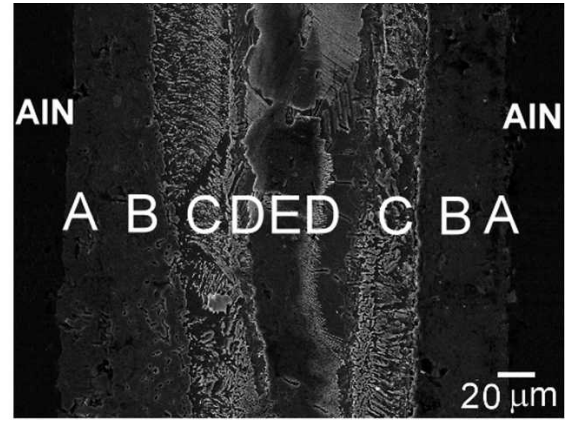

(b)

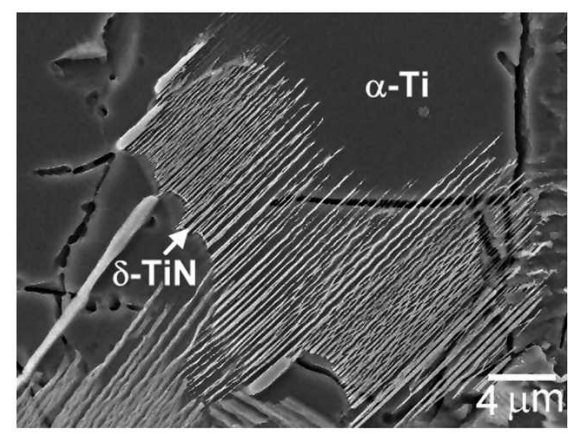

(d)

FIG. 1. Secondary electron images showing the interfacial microstructures of the AlN/Ti/AlN specimens: (a) after annealing at $1400{ }^{\circ} \mathrm{C} / 0.1 \mathrm{~h}$; (b) after annealing at $1400{ }^{\circ} \mathrm{C} / 1 \mathrm{~h}\left[\mathrm{~A}, \delta\right.$-TiN; $\mathrm{B}, \tau_{2}-\mathrm{Ti}_{2} \mathrm{AlN} ; \mathrm{C}, \tau_{2}-\mathrm{Ti}_{2} \mathrm{AlN}+\gamma-\mathrm{TiAl}+\mathrm{Ti}_{3} \mathrm{Al}_{5} ; \mathrm{D}$, a lamellar structure $\left.(\delta-\mathrm{TiN}+\alpha-\mathrm{Ti}) ; \mathrm{E}, \alpha-\mathrm{Ti}\right]$; (c) magnified secondary electron image of reaction layer $\mathrm{C}$ in (b) showing a chopped fiberlike $\tau_{2}-\mathrm{Ti}_{2} \mathrm{AlN}$ in the $\left(\mathrm{Ti}_{3} \mathrm{Al}{ }_{5}+\gamma\right.$-TiAl) matrix; (d) magnified secondary electron image of reaction layer D showing a lamellar structure of $(\delta$-TiN $+\alpha-\mathrm{Ti})$. All specimens were etched by the Kroll reagent.

specimen was much larger than $(4 D t)^{1 / 2}$ for a short annealing time. As shown in Fig. 1(b), the original Ti was replaced by a reaction zone consisting of several distinct layers, which were symmetrical with respect to the central line and designated as a reaction layer sequence of A-B-C-D-E-D-C-B-A, after annealing at $1400^{\circ} \mathrm{C}$ for $1 \mathrm{~h}$. Reaction layers $\mathrm{A}, \mathrm{B}$, and $\mathrm{E}$ represent the $\delta$-TiN, $\tau_{2^{-}}$ $\mathrm{Ti}_{2} \mathrm{AlN}$, and $\alpha-\mathrm{Ti}(\mathrm{Al}, \mathrm{N})$ solid solutions, respectively, and correspond to the results obtained in the AlN/Ti diffusion couple after annealing at $1400{ }^{\circ} \mathrm{C} .{ }^{10}$ Reaction layers $\mathrm{C}$ and $\mathrm{D}$ are different in appearance from those aluminide and/or nitride layers found in the AlN/Ti diffusion couple after annealing at the same conditions. Figures 1(c) and 1(d) illustrate the microstructures of reaction layers $\mathrm{C}$ and D, as shown in Fig. 1(b), at a higher magnification after annealing at $1400{ }^{\circ} \mathrm{C}$ for $1 \mathrm{~h}$. Figure $1(\mathrm{c})$ reveals that a chopped fiberlike phase exists in reaction layer $\mathrm{C}$. The chopped fiberlike phase and the matrix were further identified as $\tau_{2}-\mathrm{Ti}_{2} \mathrm{AlN}$ and $\left(\mathrm{Ti}_{3} \mathrm{Al}_{5}+\gamma\right.$-TiAl), respectively, using TEM/EDS analyses. Figure 1(d) displays a lamellar structure with different variations in reaction layer $\mathrm{D}$. The lamellar structure was characterized to be composed of $\delta$-TiN and $\alpha$-Ti using TEM/EDS analyses. The chopped fiberlike $\tau_{2}-\mathrm{Ti}_{2} \mathrm{AlN}$ and the Al-rich $\mathrm{Ti}_{3} \mathrm{Al}_{5}$ in reaction layer $\mathrm{C}$ and the lamellar $(\delta$-TiN $+\alpha-\mathrm{Ti})$ structure in reaction layer $\mathrm{D}$ have not been reported in previ- ous studies and are the most notable findings in the present study.

It was believed that $\alpha_{2}-\mathrm{Ti}_{3} \mathrm{Al}$ and the two-phase region $\left(\alpha_{2}-\mathrm{Ti}_{3} \mathrm{Al}+\alpha-\mathrm{Ti}\right)$, as shown in Fig. 1(a), did not exist during annealing at $1400{ }^{\circ} \mathrm{C}$ but were instead formed during cooling. The isothermal section of the Ti-Al-N system [Fig. 2(a)] ${ }^{17}$ shows that the $\alpha_{2}-\mathrm{Ti}_{3} \mathrm{Al}$ is not a stable phase at $1400{ }^{\circ} \mathrm{C}$, while the Ti-Al binary phase diagram [Fig. 2(b)] ${ }^{18}$ displays that $\alpha_{2}-\mathrm{Ti}_{3} \mathrm{Al}$ is a stable phase below $1210^{\circ} \mathrm{C}$. This implies that the $\alpha_{2}-\mathrm{Ti}_{3} \mathrm{Al}$ was precipitated from $\alpha-\mathrm{Ti}(\mathrm{Al})$ solid solution during cooling.

Figure 3(a) displays a residual $\gamma$-TiAl grain embedded in the growing $\tau_{2}-\mathrm{Ti}_{2} \mathrm{AlN}$ in reaction layer $\mathrm{B}$, as shown in Fig. 1(b), after annealing at $1400^{\circ} \mathrm{C}$ for $1 \mathrm{~h}$. Note that $\mathrm{Ti}$ reacted with $\mathrm{AlN}$ to produce $\mathrm{Al}$ and $\delta$-TiN at the initial stage. Subsequently, Al atoms diffused into Ti to form $\gamma$-TiAl. The inward diffusion of $\mathrm{N}$ atoms into the $\gamma$-TiAl resulted in the precipitation of $\tau_{2}-\mathrm{Ti}_{2} \mathrm{AlN}$ between the $\delta$-TiN and $\gamma$-TiAl layers, while the $\gamma$-TiAl layer gradually diminished. In contrast, Tian and $\mathrm{Nemoto}^{12}$ indicated that the needlelike $\tau_{1}-\mathrm{Ti}_{3} \mathrm{AlN}$ and the plate-like $\tau_{2}-\mathrm{Ti}_{2} \mathrm{AlN}$ precipitated because $\gamma$-TiAl was nitridized at temperatures above $800{ }^{\circ} \mathrm{C}$. The tendency of the phase transformation of $\gamma$-TiAl into $\tau_{2}-\mathrm{Ti}_{2} \mathrm{AlN}$, resulting from the inward diffusion of $\mathrm{N}$ atoms, can be explained by the similarity in their crystal structures. The precipitation of 


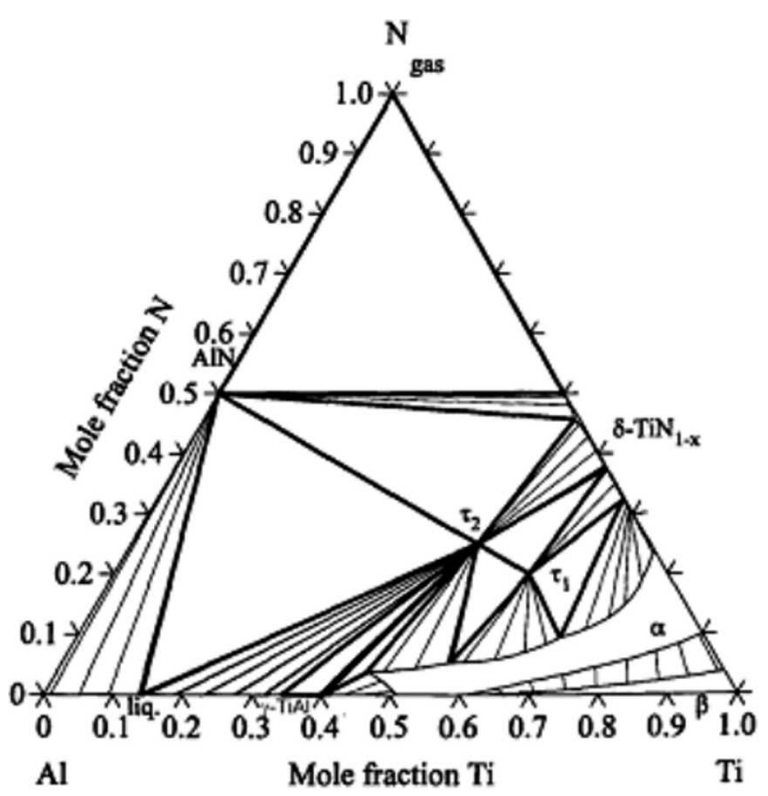

(a)

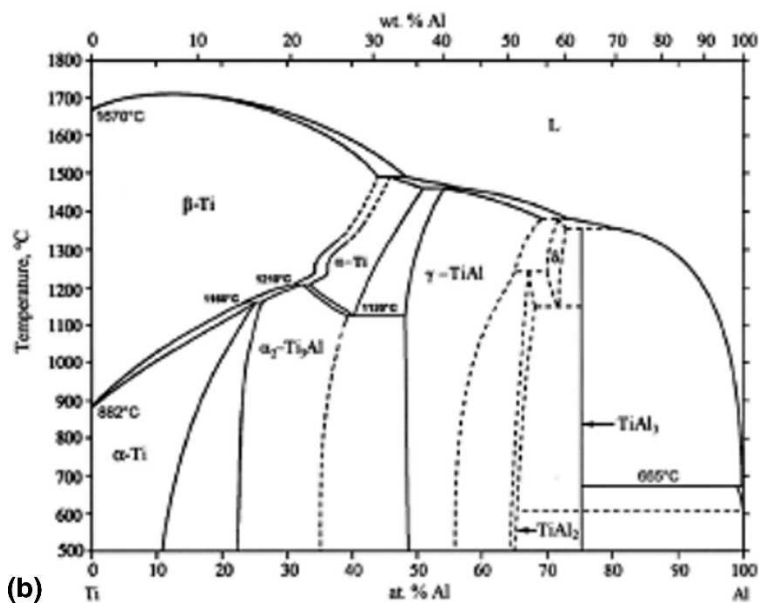

FIG. 2. (a) Isothermal section of the Ti-Al-N phase diagram at $1400{ }^{\circ} \mathrm{C}$ and (b) the $\mathrm{Ti}-\mathrm{Al}$ binary phase diagram.

$\tau_{2}-\mathrm{Ti}_{2} \mathrm{AlN}$ was predominantly governed by the substitution of $\mathrm{N}$ atoms for $\mathrm{Al}$ atoms (not $\mathrm{Ti}$ atoms) in $\gamma$-TiAl because of the strong attractive ionicity between $\mathrm{Ti}$ atoms and $\mathrm{N}$ atoms. ${ }^{19}$ Figure 3(b) shows the alternating (001) layers of $\mathrm{Ti}$ and $\mathrm{Al}$ as viewed along the [110] direction of $\gamma$-TiAl. Once each alternate $\mathrm{Al}$ atomic layer of $\gamma$-TiAl was replaced with an $\mathrm{N}$ atomic layer, the $\gamma$ TiAl was transformed into $\tau_{2}-\mathrm{Ti}_{2} \mathrm{AlN}$ with a stacking sequence $\mathrm{AB}^{\prime} \mathrm{AB} A \mathrm{~B}^{\prime} \mathrm{AB} \ldots$, where $\mathrm{A}$ and $\mathrm{B}$ represent the atomic planes of $\mathrm{Ti}$ and $\mathrm{Al}$, respectively, and $\mathrm{B}^{\prime}$ represents the substitution of an $\mathrm{N}$ atomic layer for each alternate $\mathrm{Al}$ atomic layer. Figure 3(c) shows that layers $\mathrm{A}, \mathrm{B}$, and $\mathrm{B}^{\prime}$ are parallel to the (0001) planes of $\tau_{2^{-}}$ $\mathrm{Ti}_{2} \mathrm{AlN}$ while being viewed along the direction [112̄0]. From the atomic configurations in Figs. 3(b) and 3(c), it can be inferred that $[110]_{\gamma-\mathrm{TiAl}} / /[11 \overline{2} 0]_{\tau_{2}-\mathrm{Ti}_{2} \mathrm{AlN}}$ and $(001)_{\gamma-\mathrm{TiAl}} / /(0001)_{\tau_{2}-\mathrm{Ti}_{2} \mathrm{AlN}}$.

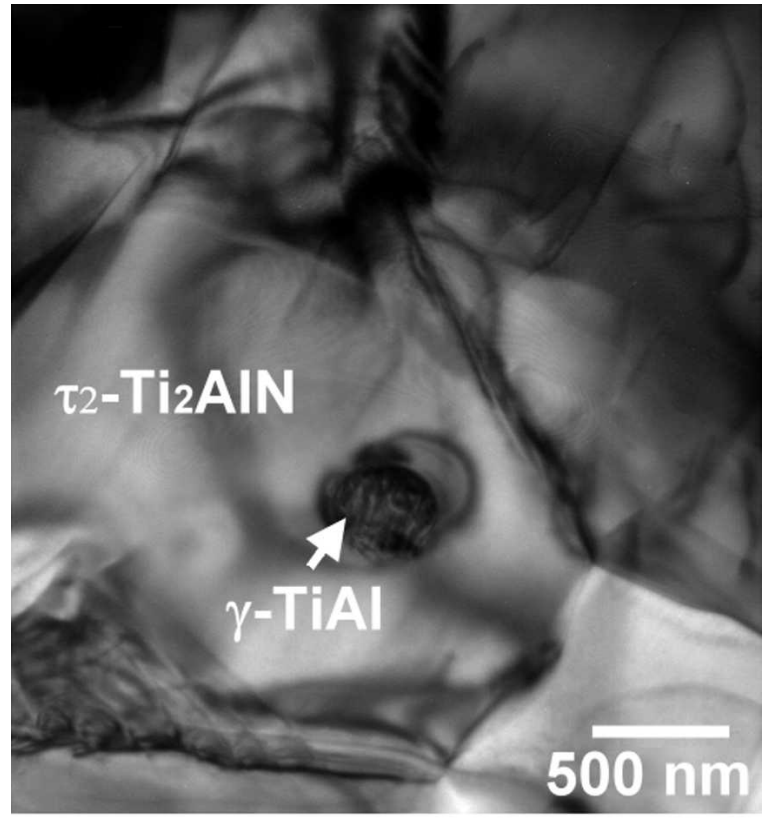

(a)

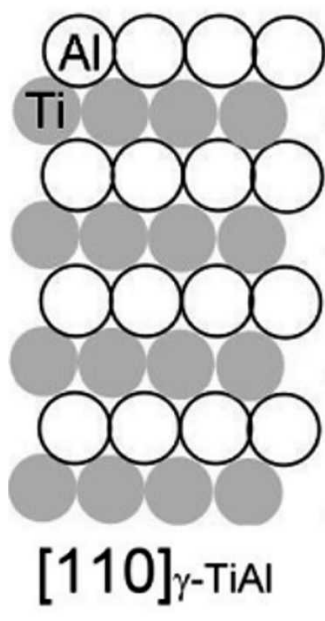

(b)

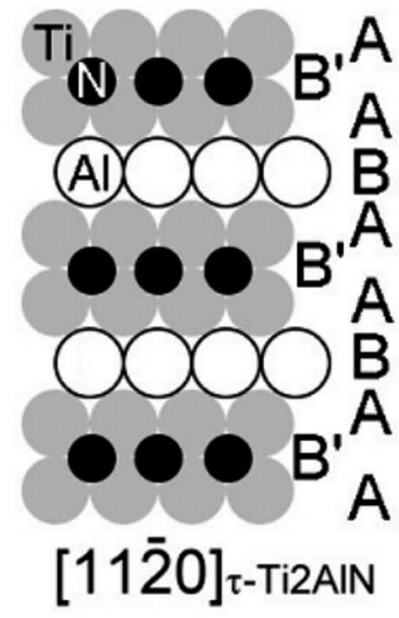

(c)

FIG. 3. (a) Bright-field image showing a residual $\gamma$-TiAl grain embedded in $\tau_{2}-\mathrm{Ti}_{2} \mathrm{AlN}$ after annealing at $1400{ }^{\circ} \mathrm{C} / 1 \mathrm{~h}$; (b) alternating (001) layers of $\mathrm{Ti}$ and $\mathrm{Al}$ viewed along the direction [110] in $\gamma$-TiAl; (c) stacking sequence $\mathrm{AB}^{\prime} \mathrm{AB} A \mathrm{~B}^{\prime} \mathrm{AB} \ldots$ of the (0001) layers viewed along the direction $[11 \overline{2} 0]$ in $\tau_{2}-\mathrm{Ti}_{2} \mathrm{AlN}$.

When $\mathrm{N}$ atoms are dissolved in $\gamma$-TiAl, two corresponding conditions are likely to arise: (i) if $\mathrm{N}$ atoms occupy the $\mathrm{Al}$ planes, then one $\mathrm{N}$ atom is surrounded by eight $\mathrm{Ti}$ atoms, and (ii) if $\mathrm{N}$ atoms occupy the Ti planes, then one $\mathrm{N}$ atom is surrounded by eight $\mathrm{Al}$ atoms. Because a strong coulomb attractive interaction exists between $\mathrm{Ti}$ and $\mathrm{N}$ atoms, the substitution of $\mathrm{N}$ atoms for a half $\mathrm{Al}$ atom in $\gamma$-TiAl is predominant from the viewpoint of the atomic configuration. As a consequence, $\mathrm{N}$ atoms were located more favorably in $\mathrm{Al}$ planes than in Ti planes.

It was unlikely that $\tau_{2}-\mathrm{Ti}_{2} \mathrm{AlN}$ precipitated due to the 
reduced solubility during cooling. Conversely, the $\tau_{2^{-}}$ $\mathrm{Ti}_{2} \mathrm{AlN}$ was most likely to precipitate as $\mathrm{N}$ atoms diffused into $\gamma$-TiAl upon annealing. The isothermal section of the Ti-Al-N phase diagram at $1400{ }^{\circ} \mathrm{C}$ [Fig. 2(a)] shows that the $\tau_{2}-\mathrm{Ti}_{2} \mathrm{AlN}$ is in equilibrium with the $\mathrm{Ti}-\mathrm{Al}$ compounds such as $\gamma$-TiAl and the $\beta$-Ti(Al) solid solution and that the solubility of nitrogen in $\gamma$-TiAl is limited. It is thus inferred that $\tau_{2}-\mathrm{Ti}_{2} \mathrm{AlN}$ is precipitated in $\gamma$-TiAl when more than 2 at. $\% \mathrm{~N}$ diffuses inward to the $\gamma$-TiAl layer upon annealing at $1400{ }^{\circ} \mathrm{C}$.

Figure 4(a) displays the precipitation of $\tau_{2}-\mathrm{Ti}_{2} \mathrm{AlN}$ in reaction layer $\mathrm{C}$, as shown in Figs. 1(b) and 1(c), after

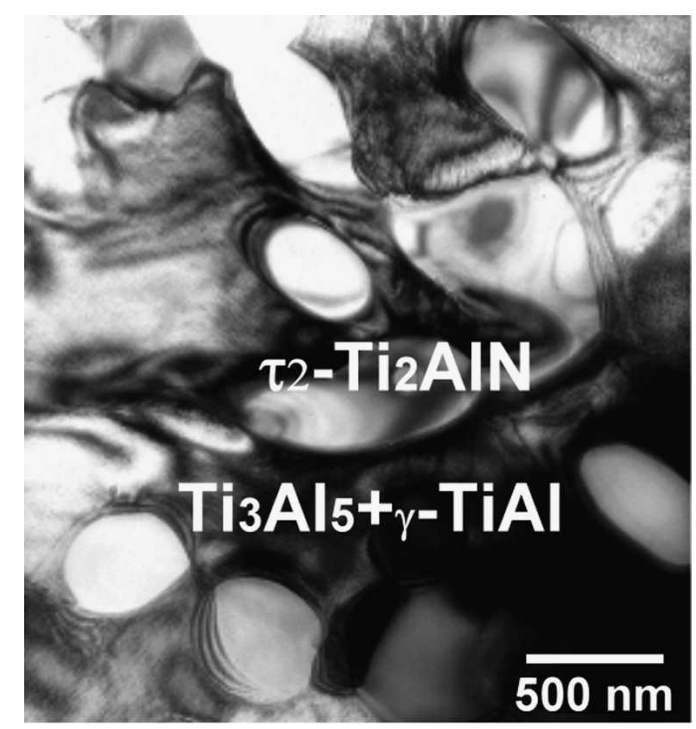

(a)

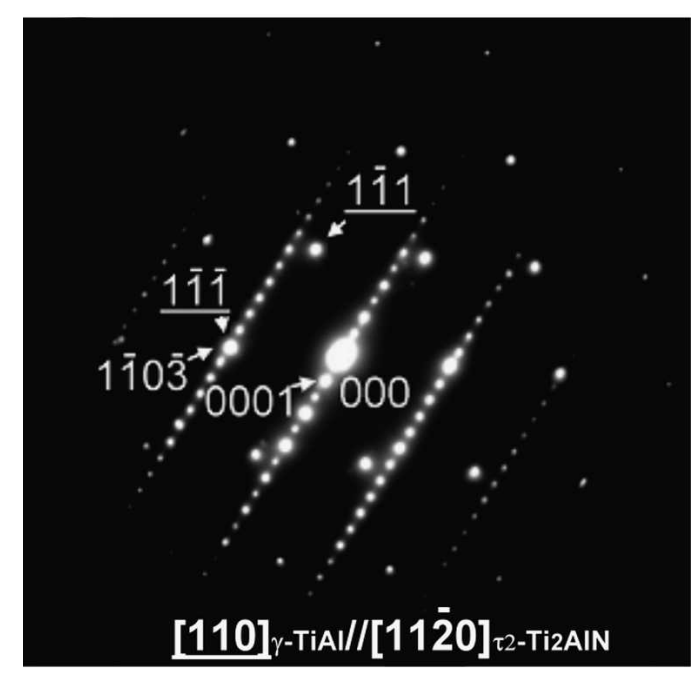

(b)

FIG. 4. (a) Bright-field image showing the precipitation of $\tau_{2}-\mathrm{Ti}_{2} \mathrm{AlN}$ in the matrix of $\mathrm{Ti}_{3} \mathrm{Al}_{5}+\gamma$-TiAl, taking place in reaction layer $\mathrm{C}$ in Fig. 1(b) after annealing at $1400{ }^{\circ} \mathrm{C} / 1 \mathrm{~h}$. (b) Superimposed SADPs of $\tau_{2}-\mathrm{Ti}_{2} \mathrm{AlN}$ and a two-phase $\left(\mathrm{Ti}_{3} \mathrm{Al}_{5}+\gamma\right.$-TiAl), showing the orientation relationships $[110]_{\gamma-\mathrm{TiAl}_{\mathrm{A}}} / /[11 \overline{2} 0]_{\tau_{2}-\mathrm{Ti}_{2} \mathrm{AlN}}$ and $(1 \overline{1} \overline{1})_{\gamma-\mathrm{TiAl}} / /(1 \overline{1} 0 \overline{3})_{\tau_{2}-\mathrm{Ti}_{2} \mathrm{AIN}}$. annealing at $1400{ }^{\circ} \mathrm{C}$ for $1 \mathrm{~h}$. Using TEM/EDS analyses, the composition of this precipitate was measured as 46.9 at. $\% \mathrm{Ti}, 23.5$ at. $\% \mathrm{Al}$, and 29.6 at. $\% \mathrm{~N}$, corresponding to the composition of $\tau_{2}-\mathrm{Ti}_{2} \mathrm{AlN}$. The superimposed selected area diffraction patterns (SADPs) [Fig. 4(b)], were taken from the region encompassing $\tau_{2}-\mathrm{Ti}_{2} \mathrm{AlN}$ and its matrix. The lattice parameters of $\tau_{2}-\mathrm{Ti}_{2} \mathrm{AlN}$ with a hexagonal crystal structure were calculated as $a=0.30 \mathrm{~nm}$ and $c=1.36 \mathrm{~nm}$. These calculated lattice parameters of $\tau_{2}-\mathrm{Ti}_{2} \mathrm{AlN}$ were consistent with those reported in literature $(a=0.2989 \mathrm{~nm}$ and $c=$ $1.3615 \mathrm{~nm}){ }^{20}$ The matrix was identified to be composed of $\mathrm{Ti}_{3} \mathrm{Al}_{5}$ and $\gamma$-TiAl as discussed below. The incident electron beam was parallel to the [011] zone axis of $\gamma$-TiAl (or $\mathrm{Ti}_{3} \mathrm{Al}_{5}$ ) and the [112̄0] zone axis of $\tau_{2^{-}}$ $\mathrm{Ti}_{2} \mathrm{AlN}$. The orientation relationships between $\gamma$-TiAl (or $\mathrm{Ti}_{3} \mathrm{Al}_{5}$ ) and $\tau_{2}-\mathrm{Ti}_{2} \mathrm{AlN}$ can be expressed as follows: $[110]_{\gamma-\mathrm{TiAl}} / /[11 \overline{2} 0]_{\tau_{2}-\mathrm{Ti}_{2} \mathrm{AlN}}$ and $(11 \overline{1})_{\gamma-\mathrm{TiAl}} / /$ $(1 \overline{1} 0 \overline{3})_{\tau_{2}-\mathrm{Ti}_{2} \mathrm{AlN}}$. They are consistent with the atomic configurations as shown in Figs. 3(b) and 3(c). Precipitation of $\tau_{2}-\mathrm{Ti}_{2} \mathrm{AlN}$ in reaction layer $\mathrm{C}$ was accompanied with the release of $\mathrm{Al}$ atoms, because $\mathrm{N}$ atoms diffused into the $\gamma$-TiAl and went to the regular sites of the Al sublattice.

Figure 5(a) displays a bright-field image of the matrix in reaction layer $\mathrm{C}$, as shown in Figs. 1(b) and 1(c), after annealing at $1400{ }^{\circ} \mathrm{C}$ for $1 \mathrm{~h}$. When the electron beam was incident along some specific directions, the $\gamma$-TiAl and $\mathrm{Ti}_{3} \mathrm{Al}_{5}$ were discernible as illustrated in Fig. 5(a). It was evident that the matrix was composed of two phases, identified as $\gamma$-TiAl and $\mathrm{Ti}_{3} \mathrm{Al}_{5}$, respectively. The SADP, as shown in Fig. 5(b), illustrates the corresponding superstructures of Al-rich $\gamma$-TiAl or $\mathrm{Ti}_{3} \mathrm{Al}_{5}$. The $1 / 2\{002\}$ superlattice diffractions resulted from the ordered $\mathrm{L} 1_{0}$ superstructure of $\gamma$-TiAl, while the $1 / 4\{100\}$ superlattice diffractions resulted from the ordering of substitutional $\mathrm{Al}$ atoms in the $\mathrm{Ti}$ sublattice of $\mathrm{Ti}_{3} \mathrm{Al}_{5}$. The 1/4(100) superlattice diffractions in Fig. 5(b) indicate that the ordering repeats once every four unit cells of the underlying $\mathrm{L} 1_{0}$ structure along the $a$ and $b$ axes. When $\tau_{2^{-}}$ $\mathrm{Ti}_{2} \mathrm{AlN}$ was formed by the replacement of $\mathrm{Al}$ atoms with $\mathrm{N}$ atoms, the released $\mathrm{Al}$ atoms diffused into the $\gamma$-TiAl, resulting in an Al-rich $\gamma$-TiAl. After Al became enriched in $\gamma$-TiAl to a certain degree, a new intermetallic compound or $\mathrm{Ti}_{3} \mathrm{Al}_{5}$ precipitated during cooling. This finding is consistent with previous studies ${ }^{21-23}$ for the ordering process of rapidly solidified Al-rich $\gamma$-TiAl alloys with fcc-based, long-period superstructures and point defects in $\gamma$-TiAl. Doi et al. ${ }^{21}$ indicated that Al-rich $\gamma$-TiAl sometimes decomposed into a two-phase structure $\left(\mathrm{Ti}_{3} \mathrm{Al}_{5}+\gamma\right.$-TiAl $)$ with undulating surfaces. The darkfield image [Fig. 5(c)] was formed by the (001) superlattice diffraction of $\mathrm{Ti}_{3} \mathrm{Al}_{5}$, marked by the circle in Fig. 5 (b), so that the bright phase represented $\mathrm{Ti}_{3} \mathrm{Al}_{5}$.

The stoichiometric $\gamma$-TiAl compound has an $\mathrm{L1}_{0}$-type 


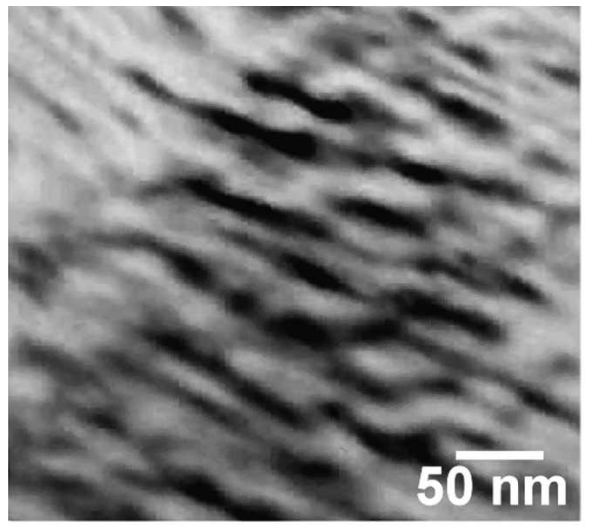

(a)

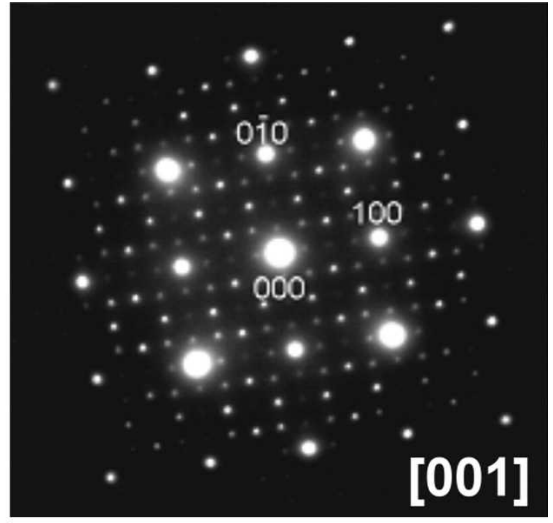

(b)

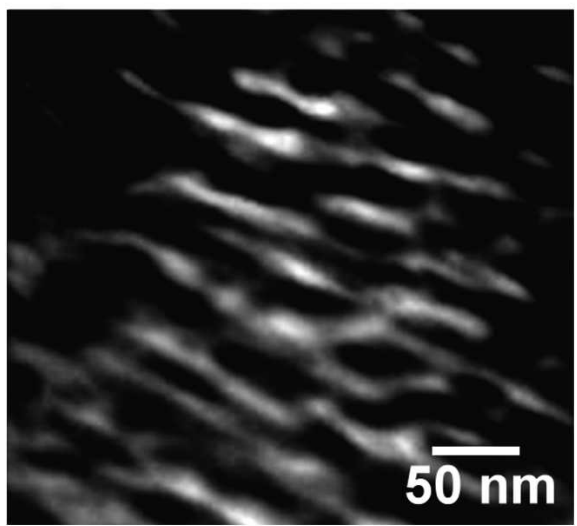

(c)

FIG. 5. After annealing at $1400{ }^{\circ} \mathrm{C} / 1 \mathrm{~h}$ : (a) bright-field image of the modulated structure of $\mathrm{Ti}_{3} \mathrm{Al}_{5}+\gamma-\mathrm{TiAl}_{\text {; }}$ (b) superimposed $\mathrm{SADPs}$ of $\mathrm{Ti}_{3} \mathrm{Al} \mathrm{l}_{5}$ and $\gamma$-TiAl, with the superlattice deflections resulting from the ordering of substitutional $\mathrm{Al}$ atoms on the Ti sublattice; (c) central dark-field image of $\mathrm{Ti}_{3} \mathrm{Al}_{5}+\gamma$-TiAl formed by the $1 / 4(100)$ superlattice diffraction of $\mathrm{Ti}_{3} \mathrm{Al}_{5}$, as marked by a circle in (b).

ordered structure with an axial ratio $c / a$ of 1.01 , and is thus considered essentially an fcc structure. This structure consists of alternate layers of $\mathrm{Ti}$ and $\mathrm{Al}$ atoms along the direction perpendicular to [001]. Fu and $\mathrm{Yoo}^{24} \mathrm{re}-$ vealed that the effect of lattice distortion due to the ordering is generally small in $\gamma$-TiAl. For Ti-rich $\gamma$-TiAl, the lattice relaxation decreases the interatomic distance of substitutional defects (Ti) with the first neighboring shell of $\mathrm{Ti}$ atoms in correspondence to a decrease in the lattice constant ratio $c / a$ to 1.00 . On the other hand, for Al-rich $\gamma$-TiAl, the lattice relaxation of the neighboring Al shell increases the $c / a$ ratio to 1.02 . Using x-ray diffraction, Swaminathan et al. ${ }^{25}$ concluded that $\mathrm{Ti}$ atoms could be replaced in an ordering manner with excess $\mathrm{Al}$ atoms in Al-rich $\gamma$-TiAl. In addition, Vujic et al. ${ }^{26}$ reported that the $c / a$ ratio of Al-rich $\gamma$-TiAl increased with the $\mathrm{Al}$ content up to 60 at. $\% \mathrm{Al}$. In Al-rich $\gamma$-TiAl, excess $\mathrm{Al}$ atoms can occupy $\mathrm{Ti}$ regular sites, and the resultant stress field is accommodated by the lattice distortion from the stoichiometric $\gamma$-TiAl. If the Al content becomes sufficiently large, an ordering of the $\mathrm{Al}$ atoms on the $\mathrm{Ti}$ sublattice takes place and eventually leads to an ordering transformation of $\gamma$-TiAl into $\mathrm{Ti}_{3} \mathrm{Al}_{5}$ by the introduction of a periodic array of defects in $\mathrm{Ti}_{3} \mathrm{Al}_{5}$.

Based upon the above discussion, the precipitation of $\tau_{2}-\mathrm{Ti}_{2} \mathrm{AlN}$ and the formation of $\mathrm{Ti}_{3} \mathrm{Al}_{5}$ can be expressed by the following reactions.

$$
\begin{gathered}
2 \gamma-\mathrm{TiAl}+\mathrm{N} \rightarrow \tau_{2}-\mathrm{Ti}_{2} \mathrm{AlN}+\mathrm{Al}, \\
3 \gamma-\mathrm{TiAl}+2 \mathrm{Al} \rightarrow \mathrm{Ti}_{3} \mathrm{Al}_{5} .
\end{gathered}
$$

Reaction (1) indicates that the $\mathrm{N}$ inward diffusion into $\gamma$-TiAl results in $\tau_{2}-\mathrm{Ti}_{2} \mathrm{AlN}$ with the release of $\mathrm{Al}$ atoms. As a consequence, the released $\mathrm{Al}$ atoms go into the matrix $\gamma$-TiAl, leading to the formation of $\mathrm{Ti}_{3} \mathrm{Al}_{5}$ as expressed by Reaction (2).

Figure 6(a) displays the bright-field image of the lamellar structure $\left[\delta-\mathrm{TiN}_{1-x}+\alpha-\mathrm{Ti}(\mathrm{Al}, \mathrm{N})\right.$ in reaction layer D, as shown in Figs. 1(b) and 1(d)], after annealing at $1400{ }^{\circ} \mathrm{C}$ for $1 \mathrm{~h}$. It is obvious that the $\delta$ - $\mathrm{TiN}_{1-x}$ has twinned. The TEM specimen for this observation was acquired from a cross-sectional SEM specimen perpendicular to the longitudinal direction of the precipitates using FIB. It thus excludes the possibility that the $\delta$-TiN ${ }_{1-x}$, as shown in Fig. 1(d), is a needlelike phase because it would otherwise show a circular image in Fig. 


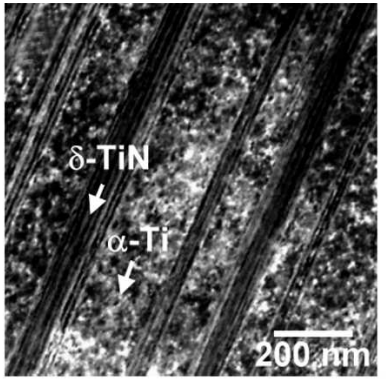

(a)
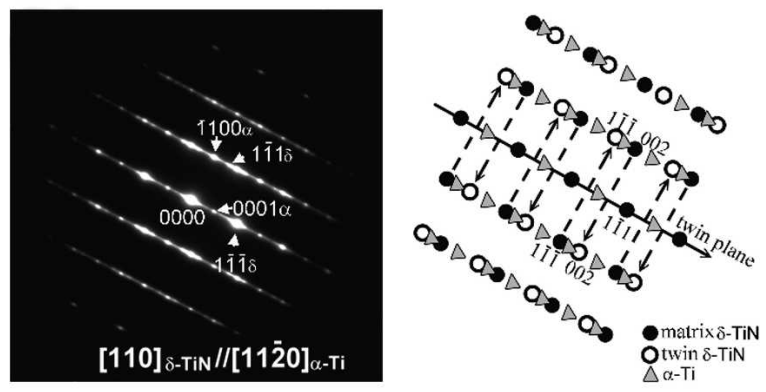

(c)

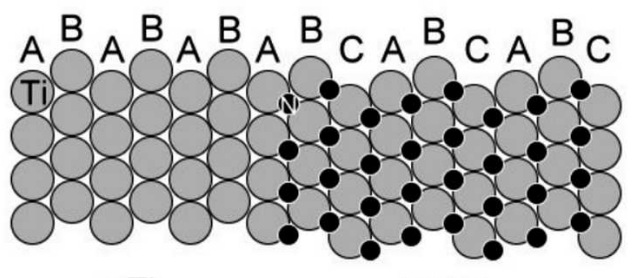

(d)

$\alpha-\mathrm{Ti}$

$\delta$-TiN

FIG. 6. (a) Bright-field image of the lamellar structure $(\delta-\mathrm{TiN}+\alpha-\mathrm{Ti})$ after annealing at $1400{ }^{\circ} \mathrm{C} / 1 \mathrm{~h}$; (b) the SADPs of $\delta$-TiN $(\mathrm{Z}=$ $\left.[110]_{\delta-\mathrm{TiN}}\right)$ and $\alpha$-Ti $\left(\mathrm{Z}=[11 \overline{2} 0]_{\alpha-\mathrm{Ti}}\right)$; (c) schematic illustration of the SADPs in (b); (d) atomic configuration at the $\delta$-TiN/ $\alpha$-Ti interface viewed along the $[110]_{\delta-T i N}$ or $[11 \overline{2} 0]_{\alpha-T i}$ direction. The TEM specimen was acquired from a cross-sectional SEM specimen along the direction perpendicular to the precipitate using FIB.

6(a). As mentioned previously, ${ }^{18} \delta$-TiN is a nonstoichiometric compound, stable in the compositional range from 30 to 55 at. $\% \mathrm{~N}$, and is usually designated as $\delta-\mathrm{TiN}_{1-x}$. The $\alpha$-Ti can dissolve $\mathrm{Al}$ and $\mathrm{N}$ in solid solution and is expressed as $\alpha-\mathrm{Ti}(\mathrm{Al}, \mathrm{N})$. Figure 6(b) reveals the SADPs of $\delta-\mathrm{TiN}_{1-x}$ and $\alpha-\mathrm{Ti}(\mathrm{Al}, \mathrm{N})$ along the zone axes $[110]_{\delta-\mathrm{TiN}_{1-\mathrm{x}}}$ or $[11 \overline{2} 0]_{\alpha-\mathrm{Ti}(\mathrm{Al}, \mathrm{N})}$ with their closely packed planes in the edge-on direction. The orientation relationships between $\delta-\mathrm{TiN}_{1-x}$ and $\alpha-\operatorname{Ti}(\mathrm{Al}, \mathrm{N})$ were identified as $[110]_{\delta-\mathrm{TiN}_{1-x}} / /[11 \overline{2} 0]_{\alpha-\mathrm{Ti}(\mathrm{Al}, \mathrm{N})}$ and $(111)_{\delta-\mathrm{TiN}_{1-\mathrm{x}}} / /$ $(0001)_{\alpha-\mathrm{Ti}(\mathrm{Al}, \mathrm{N})}$. The SADPs are redrawn, and diffracting spots are indexed in Fig. 6(c) for clarity. The extra spots were caused by the twinning of $\delta-\mathrm{TiN}_{1-x}$. The twinning and/or platelike shape leads to the streaking of the diffraction spots, as shown in Fig. 6(b). Figure 6(d) shows the atomic configurations at the $\delta-\mathrm{TiN}_{1-x} / \alpha-$ $\mathrm{Ti}(\mathrm{Al}, \mathrm{N})$ interface as viewed along the $[110]_{\delta-\mathrm{TiN}_{1-\mathrm{x}}}$ and $[11 \overline{2} 0]_{\alpha-\operatorname{Ti}(\mathrm{N})}$. It should be noted that stoichiometric $\delta$ TiN and pure $\alpha$-Ti were taken as examples, respectively, in Fig. 6(d) for simplicity. The crystal structures of $\delta$-TiN and $\alpha$-Ti are distinguished from each other based on the stacking sequences of their closely packed $\mathrm{Ti}$ atoms, which are $\mathrm{ABCABC}$... and $\mathrm{ABAB}$... , respectively. Furthermore, small $\mathrm{N}$ atoms were inserted in the octahedral interstitial sites of the $\mathrm{NaCl}$ crystal structure like $\delta$-TiN. Different stacking sequences of the Ti, Al, and $\mathrm{N}$ layers along the direction perpendicular to the closely packed planes were also found in some $\mathrm{Ti}-\mathrm{Al}-\mathrm{C}$ or $\mathrm{Ti}-$ $\mathrm{Al}-\mathrm{N}$ systems such as $\mathrm{TiAl} / \mathrm{Ti}_{2} \mathrm{AlC}, \mathrm{TiC} / \mathrm{Ti}_{2} \mathrm{AlC}, \mathrm{TiAl} /$ $\mathrm{Ti}_{2} \mathrm{AlN}, \mathrm{TiN} / \mathrm{Ti}_{2} \mathrm{AlN}$, and $\mathrm{Ti} / \mathrm{TiC}{ }^{12,27-29}$ According to the $\mathrm{Ti}-\mathrm{N}$ binary phase diagram, ${ }^{18}$ the maximum concentration of solute interstitially dissolved in $\alpha$-Ti is about 23 at. $\% \mathrm{~N}$, while $\alpha-\mathrm{Ti}(\mathrm{Al}, \mathrm{N})$ solid solution and $\delta-\mathrm{TiN}_{1-x}$ can coexist over the temperature range from 1050 to $2350{ }^{\circ} \mathrm{C}$. While a significant percentage of $\mathrm{N}$ atoms were dissolved into the Ti sublattice to form $\alpha-\mathrm{Ti}(\mathrm{Al}, \mathrm{N})$ solid solution, the remaining $\mathrm{N}$ atoms reacted with $\alpha$-Ti to form $\delta$-TiN ${ }_{1-x}$ during annealing at $1400{ }^{\circ} \mathrm{C}$.

\section{CONCLUSIONS}

(1) After AlN was bonded with a Ti foil at $1400{ }^{\circ} \mathrm{C}$ for up to $1 \mathrm{~h}$ in an Ar protective atmosphere, the AIN/Ti interfaces were investigated using analytical transmission microscopy as well as analytical SEM.

(2) Two nitride layers ( $\delta$-TiN and $\tau_{2}-\mathrm{Ti}_{2} \mathrm{AlN}$ ), one aluminide layer $(\gamma$-TiAl), and $\alpha$-Ti solid solution were initially formed due to the interfacial reactions between AlN and $\mathrm{Ti}$ on annealing at $1400{ }^{\circ} \mathrm{C}$ for $0.1 \mathrm{~h}$. Further diffusion of $\mathrm{N}$ atoms into the reaction zone played an important role of phase development at the AlN/Ti interface.

(3) Chopped fiberlike $\tau_{2}-\mathrm{Ti}_{2} \mathrm{AlN}$ was precipitated in the $\gamma$-TiAl matrix due to nitridization of $\gamma$-TiAl or the replacement of one half $\mathrm{Al}$ atom in $\gamma$-TiAl with $\mathrm{N}$ atoms after annealing at $1400{ }^{\circ} \mathrm{C}$ for $1 \mathrm{~h}$. The orientation relationships between $\gamma$-TiAl and $\tau_{2}-\mathrm{Ti}_{2} \mathrm{AlN}$ were $[110]_{\gamma-\mathrm{TiAl}} / /[11 \overline{2} 0]_{\tau_{2}-\mathrm{Ti}_{2} \mathrm{AlN}}$ and $(1 \overline{1} \overline{1})_{\gamma-\mathrm{TiAl}} / /$ $(1 \overline{1} 0 \overline{3})_{\tau_{2}-\mathrm{Ti}_{2} \mathrm{AlN}}$.

(4) After precipitation of $\tau_{2}-\mathrm{Ti}_{2} \mathrm{AlN}$ in the $\gamma$-TiAl matrix, diffusion of the released $\mathrm{Al}$ atoms into the $\gamma$-TiAl matrix resulted in an ordered aluminum-rich $\gamma$-TiAl or $\mathrm{Ti}_{3} \mathrm{Al}_{5}$ after annealing at $1400{ }^{\circ} \mathrm{C}$ for $1 \mathrm{~h}$.

(5) A lamellar structure consisting of $\alpha-\mathrm{Ti}(\mathrm{Al}, \mathrm{N})$ and heavily twinned $\delta$-TiN ${ }_{1-x}$ was formed due to the nitridization of $\alpha$-Ti after annealing at $1400{ }^{\circ} \mathrm{C}$ for $1 \mathrm{~h}$. The orientation relationships between $\delta-\mathrm{TiN}_{1-x}$ and $\alpha-\mathrm{Ti}$ were identified as $[110]_{\delta-\mathrm{TiN}} / /[11 \overline{2} 0]_{\alpha-\mathrm{Ti}(\mathrm{Al}, \mathrm{N})}$ and $(111)_{\delta-\mathrm{TiN}} / /(0001)_{\alpha-\mathrm{Ti}(\mathrm{Al}, \mathrm{N})}$.

\section{ACKNOWLEDGMENT}

This research was supported by National Science Council (Taiwan) under Contract No. NSC 96-2221-E-009-100. 


\section{REFERENCES}

1. Y. Paransky, A. Berner, and I. Gotman: Microstructure of reaction zone at the Ti-AlN interface. Mater. Lett. 40, 180 (1999).

2. Y. Paransky, I. Gotman, and E.Y. Gutmanas: Reactive phase formation at AlN-Ti and AlN-TiAl interfaces. Mater. Sci. Eng., A 277, 83 (2000).

3. Y. Paransky, L. Klinger, and I. Gotman: Kinetics of two-phase layer growth during reactive diffusion. Mater. Sci. Eng., A 270, 231 (1999).

4. Y. Paransky, A. Berner, I. Gotman, and E. Gutmanas: Phase recognition in AlN-Ti system by energy dispersive spectroscopy and electron backscatter diffraction. Mikrochim. Acta 134, 171 (2000).

5. M. Pinkas, N. Frage, N. Froumin, J. Pelleg, and M.P. Dariel: Early stages of interface reactions between AlN and Ti thin films. J. Vac. Sci. Technol. 20, 887 (2002).

6. S. Nakahata, K. Sogabe, T. Matsuura, and A. Yamakawa: One role of titanium compound particles in aluminum nitride sintered body. J. Mater. Sci. 32, 1873 (1997).

7. Y. Imanaka and M.R. Notis: Interfacial reaction between titanium thin films and aluminum nitride substrates. J. Am. Ceram. Soc. 82, 1547 (1999).

8. T. Yasumoto, K. Amakawa, N. Iwase, and N. Shinsawa: Reaction between AlN and metal thin films during high temperature annealing. J. Ceram. Soc. Jpn. 101, 969 (1993).

9. M.H. El-Sayed, M. Naka, and J.C. Schuster: Interfacial structure and reaction mechanism of AlN/Ti joints. J. Mater. Sci. 32, 2715 (1997).

10. C.H. Chiu and C.C. Lin: Microstructural characterization and phase development at the interface between aluminum nitride and titanium after annealing at $1300^{\circ}-1500^{\circ}$ C. J. Am. Ceram. Soc. 89, 1409 (2006).

11. B. Zhao, J. Sun, J.S. Wu, and Z.X. Yuan: Gas nitriding behavior of TiAl based alloys in an ammonia Atmosphere. Scr. Mater. 46, 581 (2002).

12. W.H. Tian and M. Nemoto: Precipitation behavior of nitrides in $\mathrm{L1}_{0}$-ordered TiAl. Intermetallics 13, 1030 (2005).

13. J.C. Pivin, P. Zheng, and M.O. Ruault: Transmission electron microscopy investigation of the structural transformations in titanium or TiAl implanted with nitrogen, carbon, oxygen and boron. Mater. Sci. Eng., A 115, 83 (1989).

14. A.B. Kloosterman and J.T.M.D. Hosson: Microstructural characterization of laser nitrided titanium. Scr. Metall. Mater. 33, 567 (1995).
15. K. Saito and T. Matsushima: Nitrogen ion implantation into the intermetallic compound TiAl. Mater. Sci. Eng., A 115, 355 (1989).

16. G. Cliff and G.W. Lorimer: The quantitative analysis of thin specimens. J. Microsc. 103, 203 (1975).

17. Q. Chen and B. Sundman: Thermodynamic assessment of the Ti-Al-N system. J. Phase Equilib. 19, 146 (1998).

18. J.L. Murray: Phase Diagrams of Binary Titanium Alloys (ASM International, Metals Park, OH, 1987).

19. M. Inoue, M. Nunogaki, and K. Suganuma: Chemical reaction of TiAl intermetallics with a nitrogen plasma. J. Solid State Chem. 157, 339 (2001).

20. P. Villars and L.D. Calvert: Pearson's Handbook of Crystallographic Data for Intermetallic Phases (ASM International, Materials Park, OH, 1991).

21. M. Doi, T. Koyama, T. Taniguchi, and S. Naito: Morphological changes of the $\mathrm{Ti}_{3} \mathrm{Al}_{5}$ phase formed by phase-decomposition of TiAl intermetallics. Mater. Sci. Eng., A 329-331, 891 (2002).

22. G. Sattonnay and O. Dimitrov: Long-range order relaxation and phase transformation in $\gamma$-TiAl alloys. Acta Mater. 47, 2077 (1999).

23. T. Nakano, A. Negishi, K. Hayashi, and Y. Umakoshi: Ordering process of $\mathrm{Al}_{5} \mathrm{Ti}_{3}, \mathrm{~h}-\mathrm{Al}_{2} \mathrm{Ti}$ and $\mathrm{r}-\mathrm{Al}_{2} \mathrm{Ti}$ with f.c.c.-based longperiod superstructures in rapidly solidified Al-rich TiAl alloys. Acta Mater. 47, 1091 (1999).

24. C.L. Fu and M.H. Yoo: Bonding mechanisms and point defects in TiAl. Intermetallics 1, 59 (1993).

25. S. Swaminathan, I.P. Jones, A.W.S. Johnson, and H.L. Fraser: Debye-Waller factors in off-stoichiometric TiAl: Effect of ordering of excess Al atoms on Ti sites. Philos. Mag. Lett. 73, 319 (1996).

26. D. Vujic, Z. Li, and S.H. Whang: Effect of rapid solidification and alloying addition on lattice distortion and atomic ordering in $\mathrm{L} 1_{0}$ TiAl alloys and their ternary alloys. Metall. Trans. A 19, 2445 (1988).

27. W. Lu, C.L. Chen, F.H. Wang, J.P. Lin, G.L. Chen, and L.L. He: Phase transformation in the nitride layer during the oxidation of TiAl-based alloys. Scripta Mater. 56, 773 (2007).

28. R. Yu, S. Zhang, L.L. He, W.T. Wu, and H.Q. Ye: Metal/ceramic interface in an in situ synthesized $\mathrm{Ti} / \mathrm{TiC}_{\mathrm{P}}$ composite coating by laser processing. J. Mater. Res. 16, 9 (2001).

29. Z.J. Lin, M.J. Zhuo, Y.C. Zhou, M.S. Li, and J.Y. Wang: Microstructural characterization of layered ternary $\mathrm{Ti}_{2} \mathrm{AlC}$. Acta Mater. 54, 1009 (2006). 